К.ф.н. Семкина Г.Г.

Омский государственный

университет им.Ф.М.Достоевского

\title{
О влиянии прагматических факторов на грамматические и лексические характеристики бессоюзных сложных предложений
}

Обращение лингвистики к семантическому и прагматическому аспектам предложения и высказывания позволило выявить в бессоюзных сложных предложениях характерные черты, определяющие особенности их функционирования, а также причины относительной легкости декодирования их невыраженной эксплицитно семантики слушающим и читающим. Определяющим фактором в данном случае оказывается наличие некоторых языковых признаков бессоюзных сложных предложений (БСП), которые компенсируют отсутствующий союз, позволяя адресату понимать семантику предложения.

В частности, у всех типов БСП наблюдалось соответствие структурных схем частей предложения, причем в большинстве случаев использовалась глагольная структурная схема. Например:. The machine fell down; the grass came up (JC). Такая тенденция свидетельствует о том, что бессоюзный способ выражения связи обычно используется лишь в тех случаях, когда сложное предложение строится по наиболее простой, легко прогнозируемой и декодируемой схеме, с учетом того, что аналогия и акциональность требуют, несомненно, меньше усилий для восприятия, чем различные виды несоответствий и многообразная и часто недостаточно четко очерченная статальность.

Кроме того, при любой семантике в обеих частях БСП обычно используются одинаковые формы сказуемых, причем преимущественно 
формы Simple, например: The words froze in his throat, every muscle in his body locked hard (HН). Если же формы разные, это обычно значимо для семантики и поддерживается на лексическом уровне, что опять-таки увеличивает скорость восприятия, например, в предложении противопоставления: It does not matter now, it mattered then (Mitra VIP).

Существенные данные были получены в отношении субъектных частей БСП. В частности, в предложениях одновременности субъекты обычно конкретные существительные, которые состоят в отношениях «целое - часть», например: The chamber was filled with a soft light; $\underline{\text { its walls }}$ were green and silver and its roof of gold (JRRT). В предложениях противопоставления субъекты либо выражены антонимами, либо

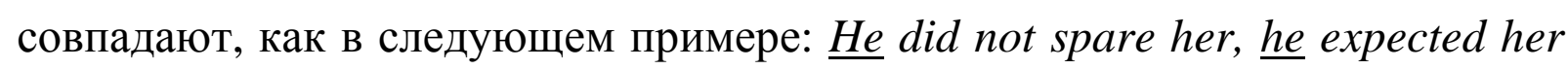
to do everything he wanted done (Mirta FtS).). Превалируют случаи анафорического соответствия или полного совпадения субъектов в БСП причины и следствия, например: The police will eventually catch the murderer, they seldom fail to do that (Mitra VIP). I had my patients and my job; I'd survive (Mitra FtS). Обобщая данные о референции субъектов в БСП отметим, что совпадение, партитивная или анафорическая связь субъектных элементов, несомненно, способствуют скорейшему и беспроблемному декодированию общего смысла всего предложения и семантических отношений его частей, поскольку в этом случае требуется минимум мыслительных операций.

БСП имеют ярко выраженные особенности и в области лексического соотношении частей. Так, предложения одновременности и следования содержат преимущественно лексику родственных семантических полей, например: He caught her wrist; she wrenched it away (JG).Предложения противопоставления всегда содержат взаимообусловленную лексику в своих частях: Physically I seemed to be all right, mentally I was shaken 
...(Mitra VIP). Более сложными оказываются лексические соотношения в БСП причины и следствия, поскольку эти типы семантических связей менее предсказуемы и более зависимы от общей текстовой ситуации.

Исследование семантической и формальной обратимости частей различных типов БСП показало, что обычно этим свойством обладают предложения одновременности и противопоставления: Сp.:My mother was a devout Catholic, my father was indifferent to religion (Mitra VIP) и My father was indifferent to religion, my mother was a devout Catholic. В предложениях следования обратимость, естественно, невозможна, что подчеркивает яркость семантики таких предложений: We had gone to the store, she bought the fish that Papa liked (Mitra FtS) и *She bought the fish that Papa liked, we had gone to the shop. Характерными особенностями в отношении обратимости обладают и БСП причины и следствия: формальная обратимость в них обычно возможна, но в этом случае семантически они превращаются друг в друга - причина становится следствием и наоборот, что противоречит коммуникативному намерению автора речи, следовательно, семантически их можно считать необратимыми, например: Worden was the uncomfortable one there - his weight was only 20 pounds instead of a normal 160 (ML) не равнозначно His weight was only 20 pounds instead of a normal 160 - Worden was the uncomfortable one there.

Таким образом, выбор имплицитного, бессоюзного способа выражения связи обычно производится автором речи для передачи более однозначных акциональных ситуаций, в то время как необходимость показа более сложных, многослойных, разносубъектных и разнородных по составу ситуаций скорее требует эксплицитного, союзного типа связи для снятия лишних преград в достижении успешности коммуникации. Следует добавить, что яркая лексическая поддержка выражаемой БСП семантики также способствует быстрому и однозначному пониманию смысловых 
оттенков как в устной, так и в письменной речи. Необходимо напомнить и о сильной интонационной маркированности БСП в устной речи используя бессоюзную связь при описании положения дел, автор речи обязательно восполняет отсутствие союза соответствующей интонацией. В письменной речи подобную роль берет на себя пунктуация, которая, к тому же, привлекает внимание читающего - ведь в большинстве исследованных примеров части БСП объединялись точкой с запятой, тире, двоеточием, а не с помощью нейтральной запятой или вообще без использования знаков препинания, что свойственно союзным сложным предложениям.

Таким образом, выбор определенных лексико-грамматических и интонационно-пунктуационных средств в БСП обусловлен прагматическими факторами, поэтому в большинстве случаев союзные и бессоюзные предложения с аналогичной семантикой не взаимозаменяемы.

Литература:

1. HH - Harrison H. West of Eden. - NY, 1996.

2. JC - Christopher J. Museum Piece. - NY, 1990.

3. JG - Galsworthy J. The Forsyte Saga. The Man of Property. - M., 2004.

4. JRRT - Tolkien J.R.R. The Lord of the Rings. Vol.1 - M., 2003.

5. Mitra FtS - Mitra R.N. Impute. Fall to Sin. M., 2005.

6. Mitra VIP - Mitra R.N. A Very Insipid Passion. - M., 2004.

7. ML - Leinster M. Keyhole - London, 2003. 